\title{
Theory and Structure of a modified Optical Fiber Turbine
}

\section{Flowmeter}

\author{
Ya-fei $\mathrm{Gu}^{1}$, Yong Zhao ${ }^{1, *}$, Ri-qing $\mathrm{Lv}^{1}$, Yang Yang $^{2}$ \\ ${ }^{1}$ Northeastern University, College of Information Science and Engineering, Shenyang \\ 110819, China \\ ${ }^{2}$ Hebei Instruments and Meters Engineering Technology Research Center, Chengde \\ 067000, China
}

\section{${ }^{*}$ Corresponding Author: Yong Zhao, zhaoyong@ise.neu.eu.cn}

\begin{abstract}
The measurement lower limit of traditional turbine flowmeter is too large to satisfy the measurement requirements of small flow rate. A modified optical fiber turbine flowmeter based on the traditional turbine flowmeter principle was purposed. The front guide vane was specially designed with a helix angle to reduce the measurement lower limit and improve the measurement sensitivity. The theoretical model for the modified flowmeter was established based on planar vector triangle of flow velocities. From theoretical analysis, the conclusion that if the helix angle of front guide vane plus the helix angle of turbine equals to $90^{\circ}$, the starting volume flow rate of turbine can get minimum value and the sensitivity of the flowmeter can get maximum value was found. The correctness of the conclusion was verified by the Computational Fluid Dynamics (CFD) simulation.
\end{abstract}

Index Terms: Turbine Flowmeter; Optical Fiber Technology; Front Guide Vane; Computational Fluid Dynamics

\section{Introduction}

Accurate flow rate measurement is the important precondition of many industry fields, such as medical, energy, petrochemical engineering, etc(1). Turbine flowmeter has become an important part of flow measurement instruments with high accuracy, good reproducibility and stability $(2,3)$. In addition, turbine flowmeter also can be used as a standard instrument to calibrate other flow measurement instruments.

The original helical turbine flowmeter was designed and primarily used in jet aircraft in the 1950s(4). After many years of research and exploration, its basic theory and the corresponding model has been nearly complete(5). However, the recent research of turbine flowmeter mainly focused on the response characteristics but not low flow rate. It was unable to satisfy the requirements of low flow rate measurement in actual production. 
With the advantages of small size, anti-electromagnetic interference immunity, capability of multiplexing and anti-corrosion, optical fiber sensors have been widely used in flow measurement fields(6). Early optical fiber turbine flowmeter belongs to reflection-impulse-type flowmeter(7). The optical fiber sensor was applied to measure the rotating speed of turbine. Despite optical fiber flow measurement has developed rapidly in laboratory recently with the employment of Fiber Bragg Grating (FBG) and Fabry-Perot (FP) cavity $(8,9)$, the reflection-impulse-type optical fiber flowmeter is still the most applied in actual production.

In addition, Computational Fluid Dynamics (CFD) simulation has become an effective method to study flow distribution with the development of computational fluid mechanics theory and computer technology. Zhen and Zhang did research on tangential type turbine flowmeter with CFD simulation in 2007(10). In 2011, Zhao and Sun used CFD to study the viscosity impact of turbine flowmeter's performance(11). In 2015, Z. Saboohi developed a model for prediction of helical turbine flowmeter with $\mathrm{CFD}(12)$.

The paper purposed a modified optical fiber flowmeter based on traditional turbine flowmeter principle. Through the special design of front guide vane, the turbine can obtain maximum driving torque. Therefore, the minimum measurable flow limit of the traditional turbine flowmeter can be decreased and the sensitivity can be increased. The conclusion was discovered from theoretical analysis. In addition, the CFD simulation was carried out to verify the conclusion.

\begin{tabular}{|c|c|c|c|}
\hline \multicolumn{4}{|c|}{ Nomenclature } \\
\hline$T_{d}$ & driving torque $[\mathrm{N} \cdot \mathrm{m}]$ & $T_{b}$ & bearing drag torque $[\mathrm{N} \cdot \mathrm{m}]$ \\
\hline$\sum f$ & sum of all drag torque $[\mathrm{N} \cdot \mathrm{m}]$ & $K$ & $\begin{array}{l}\text { The sensitivity of the flowmeter } \\
{\left[1 / \mathrm{m}^{3}\right]}\end{array}$ \\
\hline$\beta$ & helix angle of turbine $\left[^{\circ}\right]$ & $u_{i}$ & $\begin{array}{l}\text { the mean velocity in the } \\
i \text {-direction }[\mathrm{m} / \mathrm{s}]\end{array}$ \\
\hline$\omega$ & rotation speed of turbine $[\mathrm{rad} / \mathrm{s}]$ & $\alpha_{2}, \beta_{2}$ & empirical coefficients \\
\hline$F$ & force on turbine blades $[\mathrm{N}]$ & $g_{i}$ & $\begin{array}{l}i \text {-component of gravitational } \\
\text { acceleration }\left[\mathrm{m} / \mathrm{s}^{2}\right]\end{array}$ \\
\hline$\theta$ & $\begin{array}{l}\text { helixangle of front guide vane } \\
{\left[{ }^{\circ}\right]}\end{array}$ & $f_{i}$ & $\begin{array}{l}\text { the } i \text {-component of the drag } \\
\text { force }[\mathrm{N}]\end{array}$ \\
\hline$r_{1}$ & wheel shell radius $[\mathrm{m}]$ & $T_{t}$ & tip clearance drag torque $[\mathrm{N} \cdot \mathrm{m}]$ \\
\hline$r_{2}$ & top blade radius [m] & $T_{h}$ & hub fluid drag torque $[\mathrm{N} \cdot \mathrm{m}]$ \\
\hline$f$ & light impulse frequency $[\mathrm{Hz}]$ & $T_{w}$ & hub disc drag torque $[\mathrm{N} \cdot \mathrm{m}]$ \\
\hline$Z$ & number of turbine blades & $\mu_{\mathrm{t}}$ & $\begin{array}{l}\text { turbulence dynamic viscosity } \\
\text { [pa.s] }\end{array}$ \\
\hline$A$ & sectional area of pipeline $\left[\mathrm{m}^{2}\right]$ & $\sigma_{k}$ & empirical constant \\
\hline$Q_{v}$ & volume flow rate $[\mathrm{m} / \mathrm{s}]$ & $\sigma_{\omega 2}$ & empirical constant \\
\hline$Q_{V s}$ & starting volume flow rate $\left[\mathrm{m}^{3} / \mathrm{h}\right]$ & $P$ & perimeter of the opening [m] \\
\hline$\rho$ & density of fluid $\left[\mathrm{kg} / \mathrm{m}^{3}\right]$ & $R$ & radius of pipeline [m] \\
\hline$P_{k}$ & turbulence diffusion term & $V$ & velocity of fluid [m/s] \\
\hline$P_{\omega}$ & turbulence diffusion term & $F_{1}, F_{2}$ & blending function \\
\hline
\end{tabular}




\section{Structure Design and Theoretical Analysis}

\subsection{Basic Structure and Working Principles}

The structure of the modified flowmeter is consisted of metal shell, front guide vane, back guide vane, turbine, Y-type optical fiber, illuminant and photoelectric detector, as shown in Fig. 1.

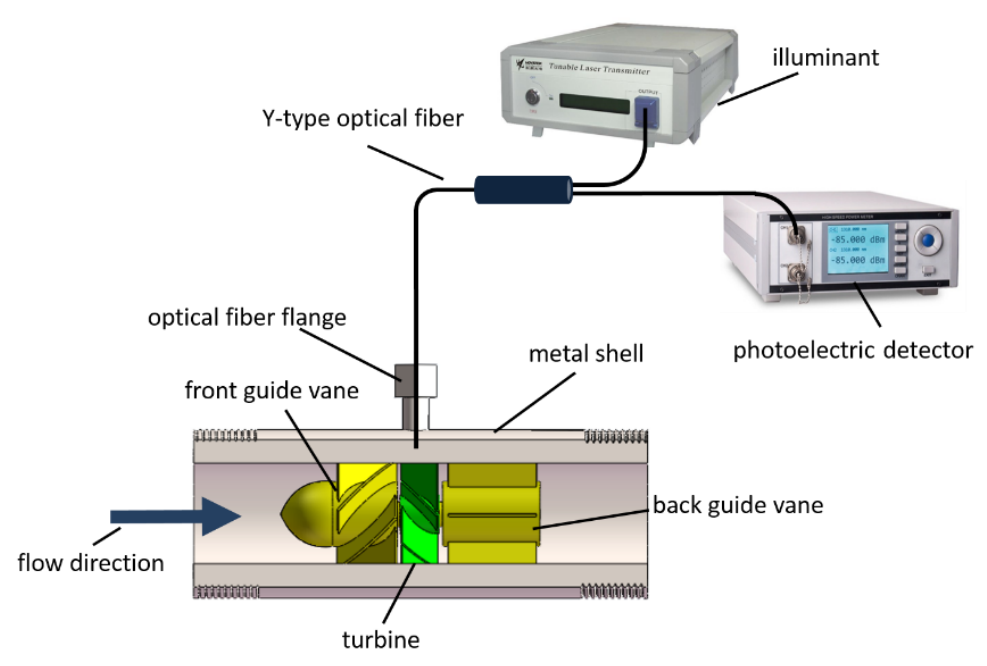

Fig. 1 structure of the modified flowmeter

As shown in Fig. 2, the front guide vane was specially designed with a helix angle which traditional front guide vane didn't have. In addition, the front guide vane provides structural support. After the process of polishing, the blades edge of turbine can reflect light. The shape of turbine and the back guide vane are shown in Fig. 3. The helix angle of front guide vane plus the helix angle of turbine equals to $90^{\circ}$. The back guide vane has the effect of the rectifier and provides structural support, too.

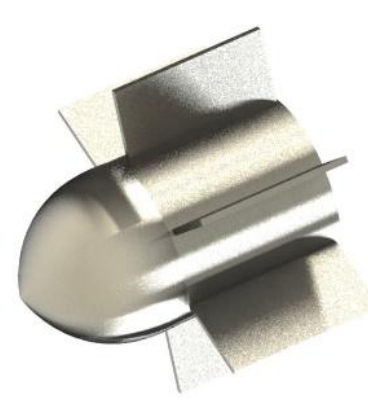

(a) traditional front guide vane

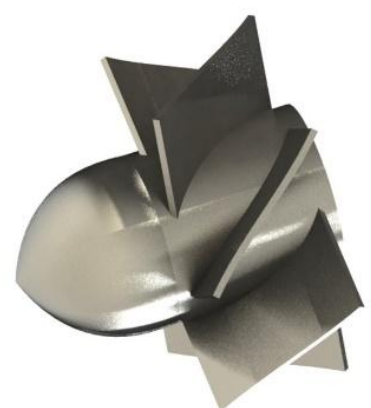

(b) special front guide vane

Fig. 2 diagram of front guide vane 


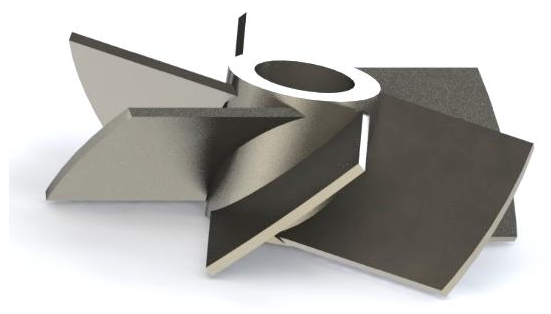

(a) turbine

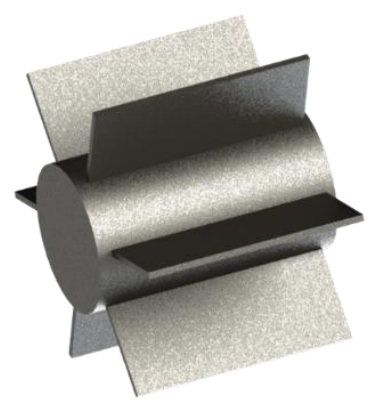

(b) back guide vane

Fig. 3 diagram of turbine and back guide vane

The working principle of primary sensor is as follows. Under the condition of axial flow direction, fluid flow through the front guide vane firstly. The velocity direction of fluid changes because of the front guide vane. Then, turbine rotates with the impact of fluid. Rotation speed is proportional to the average flow velocity. Finally, fluid flow through the back guide vane. After a long enough distance, the direction of flow restore to the original axial direction.

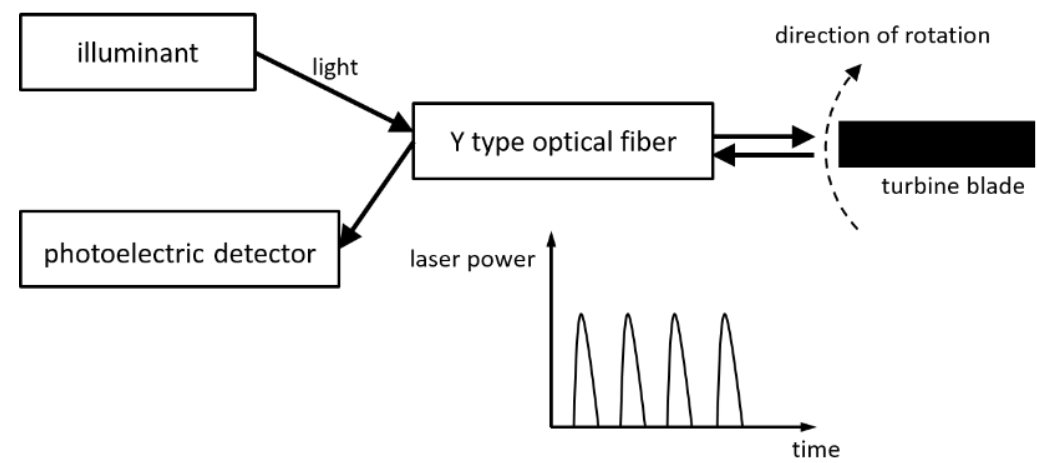

Fig. 4 schematic diagram of optical fiber sensor

The role of secondary sensor is played by the optical fiber sensor, as shown in Fig. 4. The light which comes from the illuminant pass through the branch of Y-type optical fiber to optical fiber flange. When turbine blades come to the underneath of the optical fiber flange, photoelectric detector receives a light impulse. Light impulse frequency divided by the number of blades is turbine speed. As a result, the value of flow rate can be obtained with the turbine speed.

\subsection{Theoretical analysis}

With the fluid flowing through the turbine, driving torque $T_{d}$ will be produced by the impact of fluid. The turbine will begin to rotate when driving torque overcomes fluid viscous drag torque, bearing drag torque, etc(13). When the turbine flowmeter is operating under steady flow conditions, all torques acting on the rotor must be balanced. Let the sum of all drag torque as $\sum \mathrm{T}_{f}$. The torque balance equation of the turbine flowmeter can be described as:

$$
T_{d}=\sum T_{f}
$$




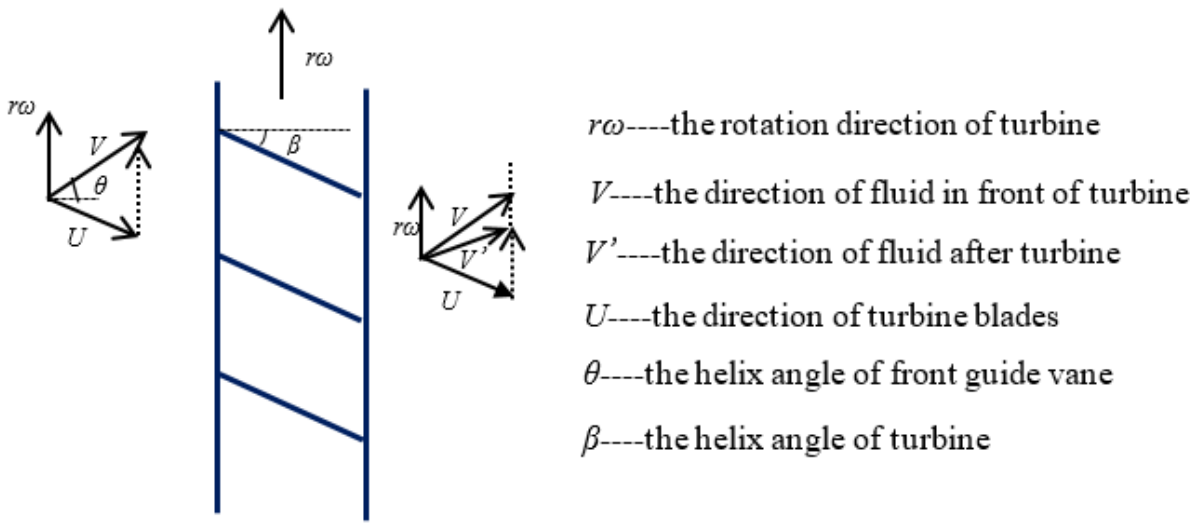

Fig. 5 planar vector triangle of flow velocities

According to the structure of flowmeter, the planar vector triangle of flow velocities was established, as shown in Fig. 5. Along the blade height direction, the torque that blade surface element bears at radius $r$ can be expressed as:

$$
\mathrm{d} T_{d}=r \mathrm{~d} F
$$

Where $\mathrm{d} F$ is the force on turbine blades. According to the theorem of momentum, $\mathrm{d} F$ is given by:

$$
\mathrm{d} F=\rho V(2 \pi r \mathrm{~d} r)[V(\cos \theta \tan \beta+\sin \theta)-r \omega]
$$

Where $\rho$ is fluid density. The integral of right side of equation (3) from wheel shell radius $r_{1}$ to top blade radius $r_{2}$ equals to the driving torque of turbine. Thus, driving torque $T_{d}$ can be expressed as:

$$
\begin{aligned}
& T_{d}=\int_{r_{1}}^{r_{2}} \rho V[V(\cos \theta \tan \beta+\sin \theta)-r \omega](2 \pi r) r \mathrm{~d} r= \\
& \frac{2}{3} \rho V^{2} \pi(\cos \theta \tan \beta+\sin \theta)\left(r_{2}^{3}-r_{1}^{3}\right)-\frac{1}{2} \pi \rho V \omega\left(r_{2}{ }^{4}-r_{1}^{4}\right)
\end{aligned}
$$

According to equations (1) and (4), turbine speed $\omega$ can be described as:

$$
\omega=\left[\frac{4}{3}(\cos \theta \tan \beta+\sin \theta) \frac{r_{2}^{3}-r_{1}^{3}}{r_{2}{ }^{4}-r_{1}^{4}}-\frac{\sum T_{f}}{\frac{1}{2} \pi \rho V^{2}\left(r_{2}^{4}-r_{1}^{4}\right)}\right] V
$$

In addition, the light impulse frequency $f$ is given by:.

$$
f=\frac{Z}{2 \pi} \omega
$$

Where $Z$ is the number of turbine blades. The volume flow rate $Q_{v}$ and flow rate $V$ are linked through:

$$
Q_{v}=A \cdot V
$$

Where $A$ is the cross sectional area of the pipe. According to equations (5), (6) and (7), $Q_{v}$ can be expressed as follows. 


$$
Q_{V}=\frac{1}{\frac{4}{3}(\cos \theta \tan \beta+\sin \theta) \frac{r_{2}^{3}-r_{1}^{3}}{r_{2}{ }^{4}-r_{1}{ }^{4}}-\frac{\sum T_{f}}{\frac{1}{2} \pi \rho V^{2}\left(r_{2}{ }^{4}-r_{1}{ }^{4}\right)}} \cdot \frac{2 \pi f A}{Z}
$$

The above equation is the theoretical relation between the volume flow rate and the light frequency.

\subsection{Characteristic Analysis}

\subsubsection{Start characteristic}

Turbine will start to rotate when the volume flow rate gets close to starting flow. At the same time, bearing drag torque $T_{b}$ is much larger than others. Therefore, other drag torque can be ignored. At the moment, $\omega$ equals to zero. According to equation (1), (5) and (8), the starting flow of turbine is as follows:

$$
Q_{V \mathrm{~s}}=A \cdot \sqrt{\frac{T_{b}}{\frac{2}{3} \pi \rho(\cos \theta \tan \beta+\sin \theta)\left(r_{2}^{3}-r_{1}^{3}\right)}}
$$

Where $Q_{V s}$ is the starting volume flow rate of flowmeter. In order to decrease the starting flow of turbine, the way that increasing value of $\cos \theta \cdot \tan \beta+\sin \theta$ can be adopted. Defining $G(\theta)$ as $\cos \theta \cdot \tan \beta+\sin \theta$, that is:

$$
G(\theta)=\cos \theta \tan \beta+\sin \theta
$$

The maximum of $G(\theta)$ can be calculated by the derivation of equation (10). At the moment, the helix angle of front guide vane $\theta$ is:

$$
\theta=90^{\circ}-\beta
$$

Therefore, if the helix angle of front guide vane plus the helix angle of turbine equals to $90^{\circ}$, the starting volume flow rate of turbine can get minimum value in the case of other parameters are fixed.

\subsubsection{Sensitivity characteristic}

According to equation (8), the sensitivity $K$ of the flowmeter can be expressed as follows.

$$
K=\left[\frac{4}{3}(\cos \theta \tan \beta+\sin \theta) \frac{r_{2}^{3}-r_{1}^{3}}{r_{2}{ }^{4}-r_{1}{ }^{4}}-\frac{\sum T_{f}}{\frac{1}{2} \pi \rho V^{2}\left(r_{2}{ }^{4}-r_{1}{ }^{4}\right)}\right] \cdot \frac{Z}{2 \pi A}
$$

In a similar way of section 2.3.1, if the helix angle of front guide vane plus the helix angle of turbine equals to $90^{\circ}$, the sensitivity of the flowmeter can get maximum value 
in the case of other parameters are fixed.

\section{CFD Simulation}

With the development of computational fluid dynamics (CFD) theory and computer technology, CFD has became an effective method to research flow distribution instead of experiment. Therefore, the CFD simulation was undertaken by the software (COMSOL) to verify the correctness of the above conclusion.

\subsection{Governing equations}

The basic equations for viscous incompressible and steady flow in Cartesian coordinates is solved by the software. The basic equations are well-known, such as continuity equation, momentum equation. For the sake of simplicity, the basic equations are described briefly as follows.

The continuity equation is mass conservation equation. The mass conservation equation and momentum equation can be described as(14):

$$
\begin{gathered}
\frac{\partial u_{i}}{\partial x_{j}}=0 \\
u_{j} \frac{\partial u_{i}}{\partial x_{j}}=-\frac{1}{\rho} \frac{\partial p}{\partial x_{i}}+\frac{\partial}{\partial x_{j}}\left(v \frac{\partial u_{i}}{\partial x_{j}}\right)-\frac{\partial\left(u_{i}^{\prime} u_{j}^{\prime}\right)}{\partial x_{j}}-f_{i}+g_{i}
\end{gathered}
$$

Where $u_{i}$ is the mean velocity in the $i$-direction, $u_{i}{ }^{\prime} u_{j}$ is the Reynolds stress, $g_{i}$ is the $i$-component of gravitational acceleration, and $f_{i}$ is the $i$-component of the drag force.

\subsubsection{Torque balance equation}

When the flowmeter is working under steady flow conditions, all torques acting on the rotor must be balanced. The torque balance equation can be described as(13):

$$
T_{d}=T_{t}+T_{b}+T_{h}+T_{w}
$$

Where $T_{d}, T_{t}, T_{b}, T_{h}, T_{w}$ are driving torque, tip clearance drag torque, bearing drag torque, hub fluid drag torque and hub disc drag torque. When the flowmeter is working normally, the $T_{h}$ and $T_{w}$ compared to other drag torque are small. Therefore, the $T_{h}$ and $T_{w}$ can be ignored.

According to torque balance equation, there must a certain rotational speed $\omega$ of turbine for specified inlet velocity. If rotational speed $\omega$ is not suitable, the resultant moment can not equal to zero. In simulation, the rotational speed is adjusted by monitoring the value of resultant moment. If the value of resultant moment is less than $10^{-3}$, turbine can be regarded as balanced. The corresponding rotational speed $\omega$ is reasonable speed. 


\subsubsection{Turbulence model}

$\mathrm{k}-\varepsilon$ and $\mathrm{k}-\omega$ model are two of the most widely used turbulence model. $\mathrm{k}-\varepsilon$ model is used for the fluid with high Reynolds number. The flow in the near wall region is not fully developed with low Reynolds number. Therefore, k- $\varepsilon$ model can not guarantee calculation accuracy in the near wall region. With the vane-blade arrangement proposed, flow separation and re-attachment will be increased in the near wall region.

In order to make simulation results close to actual conditions, the SST k- $\omega$ model of Menter was used to simulate inner flow field of the purposed flowmeter(15). The SST $\mathrm{k}-\omega$ model not only captures the core flow and the boundary anisotropy well, but also captures the distribution of the pressure loss better. The equation of the model are described as follows.

$$
\begin{gathered}
\frac{\partial(\rho k)}{\partial t}+\frac{\partial\left(\rho u_{i} k\right)}{\partial t}=P_{k}-\frac{\rho k^{3 / 2}}{l_{k-\omega}}+\frac{\partial}{\partial x_{i}}\left[\left(\mu+\frac{\mu_{t}}{\delta_{k}}\right) \frac{\partial k}{\partial x_{i}}\right] \\
\frac{\partial(\rho \varepsilon)}{\partial t}+\frac{\partial\left(\rho u_{i} \varepsilon\right)}{\partial t}=\alpha_{2} \frac{\omega}{k} P_{\omega}-\beta_{2} \rho \omega^{2}+\frac{\partial}{\partial x_{i}}\left[\left(\mu+\frac{\mu_{t}}{\delta_{\omega 2}}\right) \frac{\partial k}{\partial x_{i}}\right]+ \\
2 \rho\left(1-F_{1}\right) \delta_{\omega 2} \frac{1}{\omega} \frac{\partial k}{\partial x_{i}} \frac{\partial \omega}{\partial x_{i}} \\
\mu_{t}=\frac{\rho_{m} \alpha_{1} k}{\max \left(\alpha_{1} \omega, S F_{2}\right)}
\end{gathered}
$$

Where $P_{k}, P_{\omega}$ are turbulence diffusion terms, $F_{1}, F_{2}$ are blending functions, $S$ is shear stress tensor constant term, $\delta_{k}, \alpha_{2}, \beta_{2}, \delta_{\omega 2}$ are empirical coefficients, $\rho$ is the density of fluid and $\mu_{t}$ is turbulence dynamic viscosity.

\subsection{Mesh and boundary conditions}

In order to make the fluid state in flowmeter inlet and outlet close to full development, the upstream and downstream pipe lengths are 10 times of the inlet diameter. As shown in Fig. 6, the computational domain is divided into five parts: the front straight pipe, the front guide vane, the rotor, the back guide vane and the back straight pipe. The region of turbine was set to rotating region and other region which included front guide vane, back guide vane and pipe was set to be static area.

Firstly, a grid-independent numerical simulation is needed to analyze the simulation results. The study used five different grid densities to find the best matched grid which can make the simulation results independent of the computational grid. Table 1 shows the results of the grid independence study in terms of inlet velocity is $1 \mathrm{~m} / \mathrm{s}$, helix angle of front guide vane is $0^{\circ}$ and helix angle of turbine is $30^{\circ}$. For the purpose of saving calculation time with high accuracy, the total number of 2.2 million cells was chosen for the CFD simulation. The grid interval of upstream and downstream was relatively larger than grid interval of middle terms. The meshed computational grid of turbine is 
shown in Fig. 7 .

Because the region of turbine was rotary, other machine parts were set to be stator and real walls. The helix angle $\beta$ of turbine was set to $30^{\circ}, 45^{\circ}$ and $60^{\circ}$. When the helix angle $\beta$ of turbine was set to $30^{\circ}$, the helix angle $\theta$ of front guide vane was set to $0^{\circ}$, $30^{\circ}, 45^{\circ}, 60^{\circ}, 75^{\circ}$. When the helix angle $\beta$ of turbine was set to $45^{\circ}$ and $60^{\circ}$, the helix angle $\theta$ of front guide vane was set to $0^{\circ}, 30^{\circ}, 45^{\circ}, 60^{\circ}$.

Table 1 Grid independence results in terms of light impulse frequency for $1(\mathrm{~m} / \mathrm{s})$ flow rate.

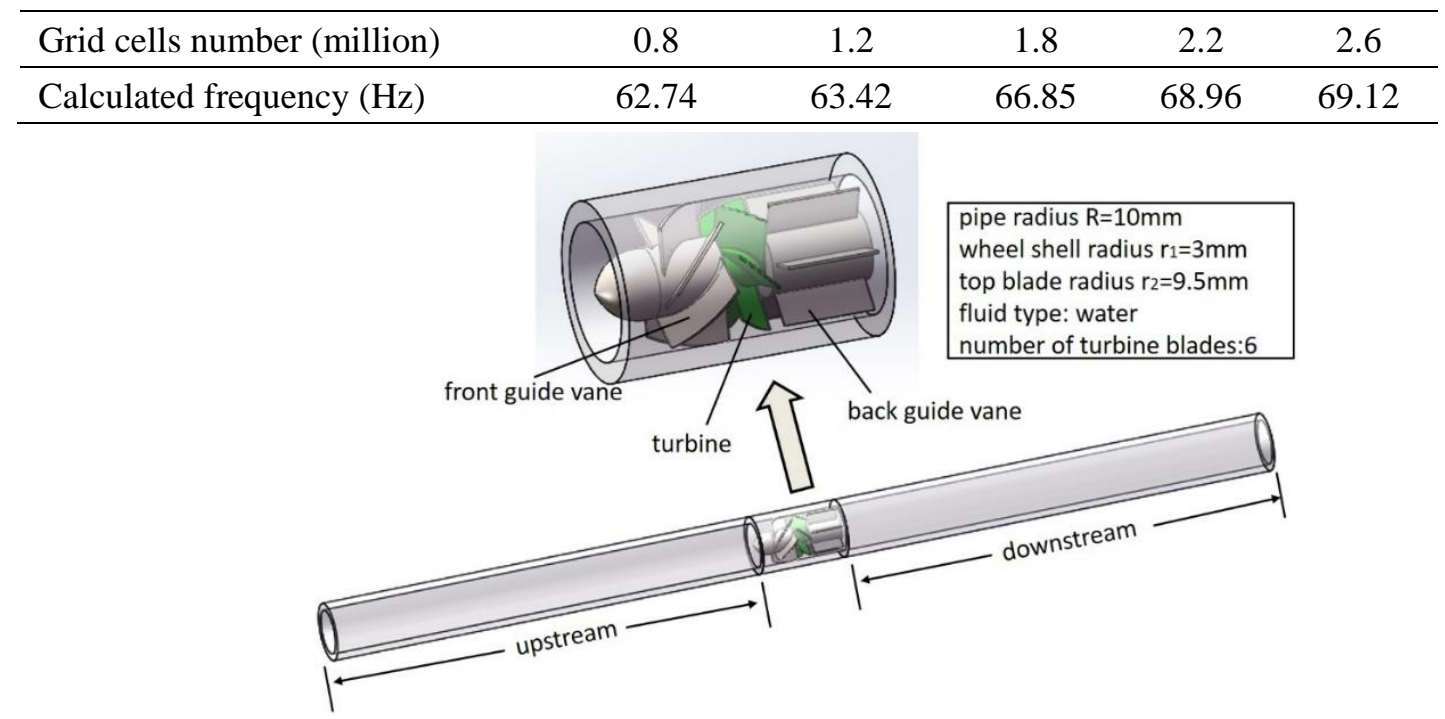

Fig. 6 the total structural model

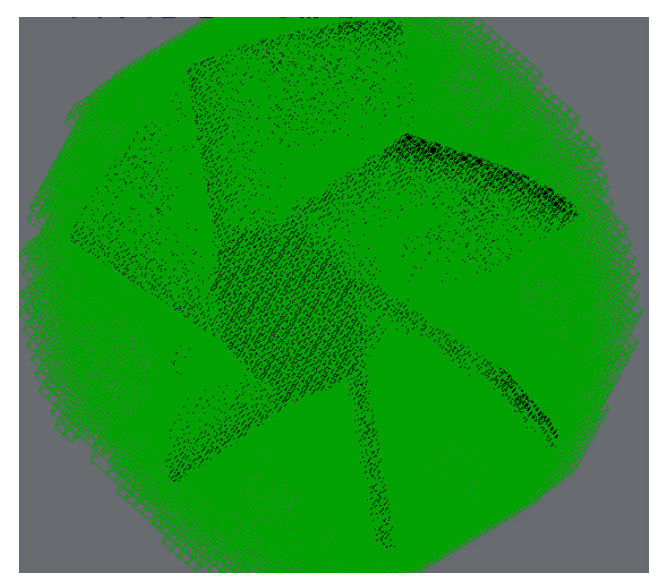

Fig. 7 mesh in region of turbine

The inlet flow rate was set to $1 \mathrm{~m} / \mathrm{s}, 2 \mathrm{~m} / \mathrm{s}, 3 \mathrm{~m} / \mathrm{s}, 4 \mathrm{~m} / \mathrm{s}, 5 \mathrm{~m} / \mathrm{s}$. According to turbulence balance equation, the rotational speed $\omega$ of turbine could be found. Using the rotational speed $\omega$ of turbine times the number of turbine blades, the light impulse frequency $f$ could be got.

\subsection{Results and discussion}

The simulation results of light impulse frequency in different conditions of inlet flow rate and helix angle of front guide vane and turbine was shown in table 2, 3 and 4. 
From table 2, 3 and 4, the relation curves of light impulse frequency and inlet flow rate in different conditions can be obtained, as shown in Fig. 8.

Table 2 light impulse frequency in terms of helix angle $\beta$ of turbine was set to $30^{\circ}$

\begin{tabular}{cccccc}
\hline$\theta$ & $1 \mathrm{~m} / \mathrm{s}$ & $2 \mathrm{~m} / \mathrm{s}$ & $3 \mathrm{~m} / \mathrm{s}$ & $4 \mathrm{~m} / \mathrm{s}$ & $5 \mathrm{~m} / \mathrm{s}$ \\
\hline $0^{\circ}$ & $68.96 \mathrm{~Hz}$ & $137.12 \mathrm{~Hz}$ & $205.68 \mathrm{~Hz}$ & $274.52 \mathrm{~Hz}$ & $343.75 \mathrm{~Hz}$ \\
$30^{\circ}$ & $121.58 \mathrm{~Hz}$ & $243.16 \mathrm{~Hz}$ & $363.96 \mathrm{~Hz}$ & $486.54 \mathrm{~Hz}$ & $606.89 \mathrm{~Hz}$ \\
$45^{\circ}$ & $134.42 \mathrm{~Hz}$ & $268.56 \mathrm{~Hz}$ & $402.88 \mathrm{~Hz}$ & $535.64 \mathrm{~Hz}$ & $671.52 \mathrm{~Hz}$ \\
$60^{\circ}$ & $141.62 \mathrm{~Hz}$ & $283.18 \mathrm{~Hz}$ & $423.86 \mathrm{~Hz}$ & $566.08 \mathrm{~Hz}$ & $707.86 \mathrm{~Hz}$ \\
$75^{\circ}$ & $132.64 \mathrm{~Hz}$ & $265.14 \mathrm{~Hz}$ & $397.42 \mathrm{~Hz}$ & $529.84 \mathrm{~Hz}$ & $663.04 \mathrm{~Hz}$ \\
\hline
\end{tabular}

Table 3 light impulse frequency in terms of helix angle $\beta$ of turbine was set to $45^{\circ}$

\begin{tabular}{cccccc}
\hline$\theta$ & $1 \mathrm{~m} / \mathrm{s}$ & $2 \mathrm{~m} / \mathrm{s}$ & $3 \mathrm{~m} / \mathrm{s}$ & $4 \mathrm{~m} / \mathrm{s}$ & $5 \mathrm{~m} / \mathrm{s}$ \\
\hline $0^{\circ}$ & $123.53 \mathrm{~Hz}$ & $247.21 \mathrm{~Hz}$ & $369.86 \mathrm{~Hz}$ & $494.14 \mathrm{~Hz}$ & $617.54 \mathrm{~Hz}$ \\
$30^{\circ}$ & $169.45 \mathrm{~Hz}$ & $338.52 \mathrm{~Hz}$ & $508.42 \mathrm{~Hz}$ & $676.92 \mathrm{~Hz}$ & $847.06 \mathrm{~Hz}$ \\
$45^{\circ}$ & $175.85 \mathrm{~Hz}$ & $351.36 \mathrm{~Hz}$ & $527.75 \mathrm{~Hz}$ & $703.68 \mathrm{~Hz}$ & $879.48 \mathrm{~Hz}$ \\
$60^{\circ}$ & $167.34 \mathrm{~Hz}$ & $333.58 \mathrm{~Hz}$ & $502.45 \mathrm{~Hz}$ & $669.38 \mathrm{~Hz}$ & $836.62 \mathrm{~Hz}$ \\
\hline
\end{tabular}

Table 4 light impulse frequency in terms of helix angle $\beta$ of turbine was set to $60^{\circ}$

\begin{tabular}{cccccc}
\hline$\theta$ & $1 \mathrm{~m} / \mathrm{s}$ & $2 \mathrm{~m} / \mathrm{s}$ & $3 \mathrm{~m} / \mathrm{s}$ & $4 \mathrm{~m} / \mathrm{s}$ & $5 \mathrm{~m} / \mathrm{s}$ \\
\hline $0^{\circ}$ & $218.64 \mathrm{~Hz}$ & $437.14 \mathrm{~Hz}$ & $655.52 \mathrm{~Hz}$ & $874.64 \mathrm{~Hz}$ & $1093.05 \mathrm{~Hz}$ \\
$30^{\circ}$ & $252.58 \mathrm{~Hz}$ & $505.62 \mathrm{~Hz}$ & $757.24 \mathrm{~Hz}$ & $1010.74 \mathrm{~Hz}$ & $1262.58 \mathrm{~Hz}$ \\
$45^{\circ}$ & $238.84 \mathrm{~Hz}$ & $477.54 \mathrm{~Hz}$ & $716.18 \mathrm{~Hz}$ & $955.36 \mathrm{~Hz}$ & $1194.72 \mathrm{~Hz}$ \\
$60^{\circ}$ & $215.65 \mathrm{~Hz}$ & $431.50 \mathrm{~Hz}$ & $646.86 \mathrm{~Hz}$ & $862.18 \mathrm{~Hz}$ & $1078.48 \mathrm{~Hz}$ \\
\hline
\end{tabular}

As shown in Fig. 8, when the helix angle of front guide vane equals to $0^{\circ}$, the front guide vane is the traditional straight guide vane. In addition, the light impulse frequency got maximum value in different situation of inlet flow rate when the helix angle of front guide vane plus the helix angle of turbine equals to $90^{\circ}$.

The simulation results of sensitivity can be got with different value of helix angle of front guide vane and turbine from Fig. 8. At the same time, the sensitivity $K$ of the flowmeter got maximum value when the helix angle of front guide vane plus the helix angle of turbine equals to $90^{\circ}$. From the theoretical analysis of section 2.2 , the fundamental cause of the maximum value of sensitivity and light impulse frequency was the increase of driving torque. With the maximum value of driving torque, the starting volume flow rate of turbine can also get minimum value in same conditions.

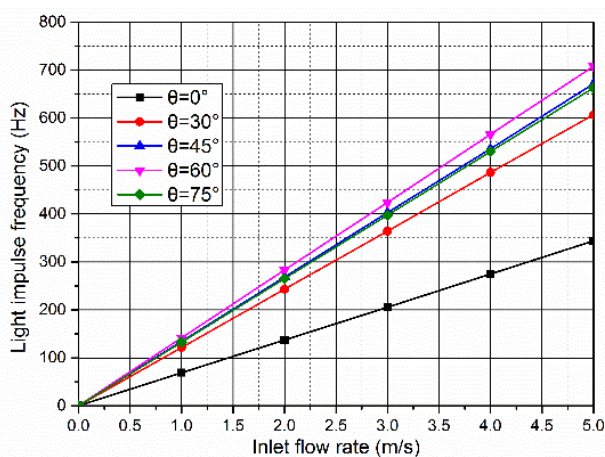

(a) $\beta=30^{\circ}$

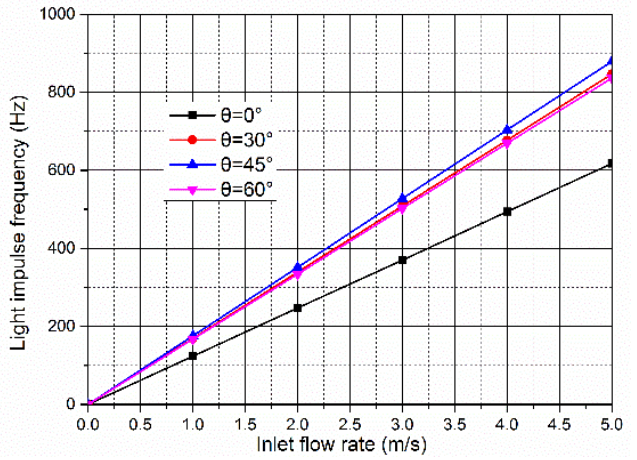

(b) $\beta=45^{\circ}$ 


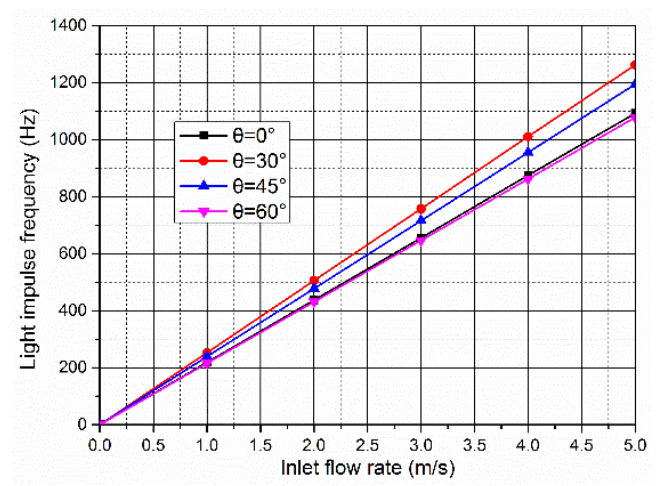

(c) $\beta=60^{\circ}$

Fig. 8 Relation curves of light impulse frequency and inlet flow rate

In addition, the pressure loss across the meter was obtained from the CFD simulation. The results was shown in Fig. 9.

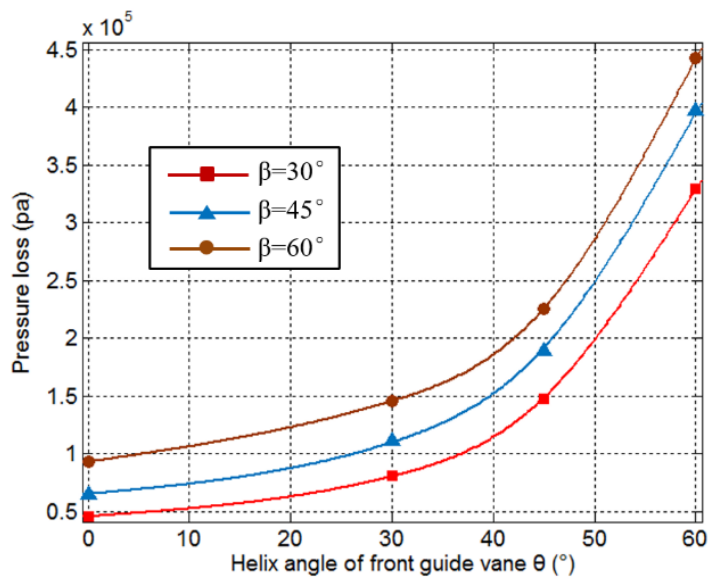

Fig. 9 Relation curve of pressure loss and helix angle of front guide vane

As shown in Fig 9, if the helix angle of turbine blades is fixed, the pressure loss would increase rapidly with the increase of angle of front guide vane. Similarly, if the helix angle of front guide vane is fixed, the pressure loss would increase rapidly with the increase of angle of turbine blades. One cause of the phenomenon is the flow area decreases with the increase of angle of front guide vane and turbine blades. Meanwhile, some pressure was consumed on the momentum of turbine. So the pressure loss increased with the increase of turbine rotational speed. Thus it can be seen that the pressure loss would increase with the the increase of sensitivity and this is the negative effect of the angle increase.

\section{Conclusion}

In this paper, a modified structure of optical fiber turbine flowmeter has been designed. In addition, the theoretical model has been established based on the planar vector triangle of flow velocities. Through the theoretical analysis, the conclusion that if the helix angle of front guide vane plus the helix angle of turbine equals to $90^{\circ}$, the starting volume flow rate of turbine can get minimum value and the sensitivity of the flowmeter can get maximum value was discovered. In order to verify the conclusion, the CFD simulation has been carried out. From the results of simulation, the conclusion 
is correct.

The pressure loss would increase with the improvement of sensitivity and this is the negative effect of the angle increase. A turbine meter is valued because of the low pressure loss and high accuracy. For practical application, sensitivity and pressure loss must be overall considered and the helix angle of front guide vane can be increased appropriately in the case of pressure loss is allowed.

The paper focused on the effects of helix angle of front guide vane and turbine on flowmeter characteristic. In the CFD simulation, the bearing drag torque was neglected. In actual application, the bearing drag torque is an important factor which affects flowmeter characteristic and it needs further research.

\section{Acknowledgements}

This work was supported in part by the National Science Foundation for Distinguished Young Scholars of China under Grant 61425003, the Chengde science and technology research and development program under Grant 20141204, the Fundamental Research Funds for the Central Universities under Grant N130104002 and N150401001, and State Key Laboratory of Synthetical Automation for Process Industries under Grant 2013ZCX09.

\section{References}

1. B. Lee, R. Cheesewright, C. Clark, The dynamic response of small turbine flowmeters in liquid flows. Flow Meas Instrum 15, 239-248 (2004).

2. D. H. Li, J. Y. Xu, Measurement of oil-water flow via the correlation of turbine flow meter, gamma ray densitometry and drift-flux model. J Hydrodyn 27, 548-555 (2015).

3. R. C. Baker, Review Turbine and Related Flowmeters: I Industrial Practice. Flow Meas. Flow Meas Instrum 2, 147-161 (1991).

4. $\quad$ F. Cascetta, Short History of the Flowmetering. Isa T 34, 229-243 (1995).

5. Y. Xu, A model for the prediction of turbine flowmeter performance. Flow Meas Instrum 3, 37-43 (1992).

6. S. Takashima, H. Asanuma, H. Niitsuma, A water flowmeter using dual fiber Bragg grating sensors and cross-correlation technique. Sensors and Actuators A: Physical 116, 66-74 (2004).

7. H. P. Ma, L. H. Liu, L. M. Yang, L. Xin, Q. H, Detection of gas turbine dynamic gap with total optical fiber system. PROCEEDINGS OF THE SECOND INTERNATIONAL SYMPOSIUM ON INSTRUMENTATION SCIENCE AND TECHNOLOGY 3, 253-258 (2002).

8. J. Cheng, W. J. Zhu, Z. W. Huang, P. B. Hu, Experimental and simulation study on thermal gas flowmeter based on fiber Bragg grating coated with silver film. Sensor Actuat a-Phys 228, 23-27 (2015).

9. Y. Li, G. F. Yan, L. Zhang, S. L. He, Microfluidic flowmeter based on micro "hot-wire" sandwiched Fabry-Perot interferometer. Optics Express 23, 9483-9493 (2015).

10. Z. Wang, T. Zhang, Research on tangential type turbine flowmeter based on simulation. 2007 leee International Conference on Mechatronics and Automation, Vols I-V, Conference 
Proceedings, 3094-3099 (2007).

11. J. L. Zhao, L. J. Sun, T. Zhang, L. Cao, in Adv Mater Res-Switz, R. Esa, Y. W. Wu, Eds. (Trans Tech Publications Ltd, Stafa-Zurich, 2011), vol. 301-303, pp. 1283-1288.

12. Z. Saboohi, S. Sorkhkhah, H. Shaken, Developing a model for prediction of helical turbine flowmeter performance using CFD. Flow Meas Instrum 42, 47-57 (2015).

13. R. C. Baker, Review Turbine and Related Flowmeters: II, theoretical and experimental published information. Flow Meas Instrum 4, 147-161 (1993).

14. H. Kang, S. U. Choi, Turbulence modeling of compound open-channel flows with and without vegetation on the floodplain using the Reynolds stress model. Adv Water Resour 29, 1650-1664 (2006).

15. F. R. Menter, Two-Equation Eddy-Viscosity Turblance Models for Engineering Applications. AIAA Journal 32, 1598-1605 (1994). 